\title{
We All Came From Somewhere
}

\author{
Elizabeth Coombes ${ }^{1}$ * \\ 1 University of South Wales, UK \\ *elizabeth.coombes@southwales.ac.uk
}

Received: 22 February 2017 ; Accepted: 20 November 2017 ; Published: 1 March 2018

Editor: Avi Gilboa Reviewer: Lucy Bolger

\begin{abstract}
This reflection on practice concerns a short-term music therapy project undertaken in 2014 with asylum seeking families in a major city in S. Wales. The project was designed to support these families in settling in their new home, and was the first music therapy initiative for the charity who funded it. The work itself caused the therapist to reflect on the countertransference engendered by the experience and how this aspect of the work enabled her to gain a deeper understanding of issues faced by those who find themselves seeking asylum in another country.
\end{abstract}

Keywords: music therapy, asylumseekers, countertransference, reflection

\section{Prelude}

In 2014, I led an 8-week music therapy project for asylum seeking families with preschool children. The work was located in a major city in South Wales. Funding was provided by a large UK charity dedicated to improving the lives of the most vulnerable children and young people in society. The purpose of the work was to make connections between newly dispersed asylum-seeker families and the charity and to assist them in becoming part of their new community. The charity was interested in broadening the range of therapies it offered and wanted to use unallocated funds to explore the option of music therapy.

The original idea for the project had developed from a chance meeting with a manager of part of the charity's provision. We had met at a play therapy clinic opening and had discovered a mutual interest in developing services for asylum-seeking families. There was at the time a paucity of therapeutic support for this population in the city. My thinking around the difficulties of transitioning to a new country and culture and how music therapy might play a part in supporting this population piqued the manager's interest. A few weeks after the meeting, I received an email from the charity asking me to devise a short project for the client group mentioned above, and I began to seek out ideas and frameworks to help me think about this work.

Although I had experience in working using music therapy and skillsharing in the Occupied Palestinian Territories (OPT) (Coombes, 2011; Coombes \& Tombs-Katz, 2017), I had not worked in my own country, Wales, with the asylum-seeker population. I located a body of literature discussing music therapy and music work in this area of practice in a multitude of geographical locations (Behrens, 2012; Storsve, Westby, \& Ruud, 2010; Sutton 2002). There were descriptions of work in clinical, community and school settings in the countries into which refugees (for so they were designated in these papers) had been placed (Choi, 2010; Jones, Baker \& Day, 2004; Orth, 
2005; Signorelli \& Bright, 2006). Whilst these were of interest in that they discussed matters relevant to the population in general, it was not until I located the writing of Zharinova-Sanderson (2004) that I began to gather my thoughts in a more coherent manner. She talked about the potential for musicking with this client group to build trust and community engagement, moving from a position of social isolation to one of integration. Her thinking appeared to support the needs of the target client group for this pilot: asylum-seeker families with young or pre-school children.

As well as the immediate issues of settling in a new community, there were also the well established frameworks of attachment theory to consider (Ainsworth, 1963; Bowlby, 1969). It seemed that due to the pressures of the situation in which they were living, some caregivers may have been struggling to be emotionally accessible to their children. This could disrupt the early relating experiences so important for the child's development and relationship between carers and child. There seemed to be links showing the potential for the development of healthy attachment styles and music therapy work which supported my position (Pasiali, 2012).

There is a wealth of writing on the topic of musical connections with parent-child interaction and bonding. Amongst others, Abad and Edwards (2004) discussed the inviting nature of such interactions; Oldfield, Adams and Bunce (2003) described how using music could be seen as a natural extension of communication between parent and child. Oldfield and Bunce (2001) also suggested that short-term music therapy with mothers and children can be an effective treatment for certain client groups. There was, then, the potential for this model of structured sessions with social time for conversation after sessions to be a useful framework for this pilot.

I was also mindful of my own position as insider/outsider in the work. As a Welsh music therapist, would the clients' perceptions of me as an authority figure impact negatively on their experiences in the group? What was I bringing to the group musically and in terms of preconceived notions, perhaps? Bridges (2001), writing about what he described as outsider research, posits that only those who have been part of a particular experience can understand that experience. He also suggested that utilising existing frames of reference relevant to the outsider themselves and their culture may actually be damaging to the work being undertaken. My background as a psychodynamically trained music therapist, with experience of the model of infant observation developed by the Tavistock Clinic in London, seemed incredibly foreign to the worlds of the asylum-seeker families. However, my previous work in the OPT, in which I had utilised these very frameworks, as well as those of Winnicott $(1960,1971)$ and Stern (2001), had provided a useful underpinning for my thinking. Whilst it was imperative to be mindful of these matters, I felt I could work in an appropriate way with these families and offer them a useful experience in what was to be their new home.

I was allocated a support worker to assist me during the sessions. Gemma was a primary school teacher by training and was now working for the charity. She was to make the practical arrangements associated with the project, including locating the families, arranging the initial meetings and weekly session times. It was the first project she had set up and worked on in this position. Our first task, once the families had been offered a place on the project was to meet each of them individually in their homes, before the work started, to build up a rapport. We wanted to offer a personal touch to what otherwise could have seemed a rather intimidating invitation by letter. None of the families offered the project contained a male figure, so the group in the event was a mother-child group, with two mothers bringing two children with them to the group.

\section{The first home visit}

It was a clear, cold, breezy day in January when we drove across town, heading south and passing under the railway track. There were rows of terraced houses, small shops, and curving streets that pulled you in different directions. 
We squeezed the Fiat Uno into a parking space and climbed out, blinking in the sunlight and shading our eyes to read the street names. I carried a bag of percussion instruments meant to invite and entice. Gemma packed a sheaf of papers, permission slips and explanations translated into several languages. We were prepared.

Or were we? Disorientated, we turned around, craning and twisting our necks. The wrong street - or was it? The name was almost right. The house numbers weren't in order; some were missing. A nagging feeling crept over me, like something picking at the back of my neck. This wasn't the address, but it had to be. We checked our watches; we mustn't be late. Gemma took action and started knocking at a door that had a number near to the one we were seeking. No answer. Anxiety rose in my stomach. I crossed the road and stood in a patch of sunlight allowing the warmth to fill my body. There was a bakery on the corner. The smell of freshly baked goods wafted over to us. I entered and asked for the address. "Oh yes, love. It's a new build. Just behind here. Hard to find. Everyone misses it". It wasn't on the map. No way to tell. No way to know we were nearly there. We had to ask.

Relieved, I called to Gemma, and we walked the few steps to the small mews houses tucked away in a cul-de-sac. The house numbers were plain to see. We took a breath and knocked on the door.

\section{Reflections}

Feelings of "being lost" were very present for me throughout this project. At the time, while the work was ongoing, it was hard to think about this, hard even to identify it in the moment. It was as though in order to work with the group, these feelings had to be managed and held well enough to continue the music therapy. Perhaps there was something unbearable about them. It seems now, some time later, that these emotions were an important part of the countertransference not only for this particular piece of work, but also potentially for the client group of asylum seekers itself. It is interesting to note, however, that those who have worked with and written about their experiences with asylum-seekers do not reference this particular aspect of the work in any detail.

Mary Priestley (1994) emphasised the importance of using countertransference responses to deepen understanding and direct the responses of the therapist to the clients' material. She identified two kinds of countertransference, both of which must be worked with to enable the therapist to work effectively. Empathic countertransference (E-countertransference), where the therapist develops a psychological awareness of the processes at work through an empathic identification with the clients, served to allow me to experience these feelings and use them as a frame of reference for this work. Her description of these feelings as a form of resonance supported me in staying with this work in an emotional sense, as at times, it felt very difficult to remain present with the group. The complementary countertransference (C-countertransference) occurs where the therapist identifies with strong relationships from the clients' past. Here I felt there was an ambivalence present for the families. Although we had few details about how the families had arrived in the UK, the bits and pieces of information we did have showed a fragmentation of family life. While it seemed that there were positive relationships in the past, there were also some other more troubling aspects of their lives that seemed omnipresent. In this group setting, it seemed that the families were working towards providing nurturing relationships and environments for their children. It was important that I continually check-in with myself by remaining curious and vigilant as to my interventions and the communications I made with the group. By working with this construct, I felt that even in this short pilot, I was able to support the mothers to work with their feelings and feel supported by the project. It also seemed that I was able in some way to be part of their experience, despite Bridges (2009) discussion of the impossibility of this for the outsider.

On that first day of the project when we met further members of the asylum-seeker family group, "being lost" became a thread woven through the fabric of the encounters. The second home we visited was also challenging to access. Although we could see the house, somehow we couldn't work out how to gain access to the parking in 
front of it. We ended up driving round in circles, glimpsing it a number of times before we could see how to draw nearer and park outside. The third home had two front doors on different sides of the house. We spent 20 minutes knocking on the wrong door before realising there was in fact another entrance. At the end of the day, we were exhausted; I wanted nothing more than to be in my own home, surrounded by familiar belongings and people. I felt a strong sense of dislocation after a day spent visiting three recently resettled families, and this needed to be countered by self-nurturing experiences to bring some balance to the day.

The symbolic meaning of these practical struggles to access the clients and "being lost" in the process was a very powerful one. Thoughts explored when devising the project were to introduce families to the culture of Wales, their new home, while reciprocally learning about their indigenous culture. Each of the families had children in school or about to access school, and part of their experience would be learning Welsh and being taught Welsh songs. This project, then, could form a bridge between the worlds of their indigenous culture and their new home, as suggested by Scroope and Signorelli (2010). Freeman-Sharpe (1978) discussed the power of curiosity in developing psychological understanding from the point of view of therapist and client. This was something I strove to maintain, as for me it signalled an openness to learn and experience, something I was hoping the families would also feel. Ansdell (2014) wrote compellingly of the importance of belonging in a community and how 'musicking' provides an opportunity for this to happen. Somehow, my feelings had to be contained and transformed to enable me to engage and attune with the group, assisting them to move towards a position of hopefulness about their current situation. Using Priestley's countertransference framework undoubtedly supported me in my way of working, offering guidance and support when at times the turmoil in the group felt too chaotic to work with.

As the short project progressed, moments of being 'in-tune' with each other developed; one child brought some exuberant Albanian folk dance moves to the 'Move to the Music' section. On another occasion, rhythms akin to those familiar to the family from Pakistan emerged with ululation and hand clapping as we improvised together. Questions about the Welsh foods we offered in the tea and cake time after the music led to curiosity about each other's cuisine. Common ground was emerging, and families began to arrive by bus or on foot, declining our offers of taxis to help them attend the sessions. They were finding their own way, and so were we.

Nonetheless, the group was still fragile. The Albanian family missed one session, and the following week we discovered that they had got off at the wrong bus stop. They had wandered around the area not being able to find the centre; the 3-year old sobbing and fighting his mother with disappointment, the 8-week old baby screaming in the pushchair. She hadn't felt able to ask for help and had only just managed to find her way home in time to pick up her other children from school. In that week's session, the soft, quiet music that often arose near the end, where families had time to cuddle and be together without words seemed very important. The intrusive reminder of the delicate state of the families was a sobering one; it hung over the group like a cloud that day and remained long after the session had ended. The sense of fragility was real; many families had been moved to different cities multiple times, and although they were now regarded as settled in Wales while their refugee status was determined, they shared their thoughts that any day, for some reason, any reason, no reason, they could be moved again.

When the 8-week project ended, we presented each child with a certificate of achievement, detailing special moments in the group. An 18-month-old boy was praised for 'good listening'. We remembered his face shining and beaming as he watched his older brother playing with the castanets, his own fingers grasping at them as his mother supported him. Another certificate mentioned kindness to the very young baby girl in the group; one boy had been very rambunctious at the beginning of the project but had been able to show tenderness towards younger members. The mothers were very appreciative of these offerings. 
As for the mothers themselves, they cried during the last session. They all said how important the home visits at the start of the work had been. They had given them a sense that we, the therapist and project worker were ordinary people, eager to learn about their culture. They felt the city could be their home too. It was very moving to hear these words.

\section{Conclusion}

Although the music therapy project had ended, the charity offered the families other ways of engaging. There were trips that the families could join, and other general play groups the charity ran that they could access. They were all keen to continue meeting at the centre and this seemed to bode well for future work with the families.

The charity was preparing an evaluation of the project, but I was never to see this. Gemma was going on maternity leave at the end of the week in which the project finished, and in fact this last session was the end of my involvement with the families and this project. Despite attempting to access the final report, it was not forthcoming. I wondered if it had in fact ever been finalised and signed-off. Funding issues meant the pilot, which we all felt had fulfilled its aims of improving community engagement and supporting families as they began to make connections with the area, was never repeated. In one sense, then, the families were lost to me. The work itself seemed to have vanished as swiftly as it had arrived.

The project itself, however, did validate the theoretical approaches and frameworks I chose to use. My own psychodynamic training was of use in my reflections and supervision in unpicking the countertransference and working with the emotions present in the group. Oldfield and Bunce's (2003) project work gave a model for my own, and I felt that there was room for this model to develop. In writing this article, I came across a paper by Comte (2016), and this has given me food for further thought regarding the frameworks we ourselves import into work with this client group. There is further thinking and writing to be done to explore these matters.

For myself, 3 years later, I still find it hard to shake the feelings of disorientation and of being off-balance that this work evoked. What was striking at the time, and remains so, is that some level of a commonality of experience between the group and myself emerged. Being lost, not knowing where to go; these moments were powerful and have now woven themselves into my world-view and inform my work with this client group. As the poet Benjamin Zephaniah ("We Refugees", 2017) wrote:

We can all be refugees

Sometimes it only takes a day

Sometimes it only takes a handshake

Or a paper that is signed.

We all came from refugees

Nobody simply just appeared,

Nobody's here without a struggle,

And why should we live in fear

Of the weather or troubles?

We all came from somewhere.

\section{References}

Abad, V., \& Edwards, J. (2004). Australian Journal of Music Therapy, 15, 3-17.

Ainsworth, MDS. (1963). The development of infant-mother interaction among the Ganda. In

B. M. Foss (Ed.), Determinants of infant behavior II (pp. 67-104). London, England: Methuen.

Ansdell, G. (2014). How music helps in music therapy and everyday life. London, England:

Ashgate Publishing Ltd.

Behrens, G. (2012). Use of traditional and nontraditional instruments with traumatized children in Bethlehem, West Bank. Music Therapy Perspectives, 30, 196-202, https://doi.org/

10.1093/mtp/30.2.196. 
Bowlby, J. (1969). Preface. In B. M. Foss (Ed.), Determinants of infant behavior IV (pp. xiii-xiv). London, England: Methuen.

Bridges, D. (2001). The ethics of outsider research. Journal of Philosophy of Education, 35(3), 371-386, https://doi.org/10.1111/1467-9752.00233.

Bridges, D. (2009). Education and the possibility of outsider understanding. Ethics and Education, 4(2), 105-123, https://doi.org/10.1080/17449640903326714.

Choi, C. M. (2010). A pilot analysis of the psychological themes found during the CARING at Columbia-music therapy program with refugee adolescents from North Korea. Journal of Music Therapy, 47, 380-407, https://doi.org/10.1093/jmt/47.4.380.

Comte, R. (2016). Neo-colonialism in music therapy: A critical interpretive synthesis of the literature concerning music therapy practice with refugees. Voices: A World Forum for Music Therapy, 16(3), https://doi.org/10.15845/voices.v16i3.865.

Coombes, E. (2011). Project Bethlehem: Training educators and health workers in the therapeutic use of music in the West Bank. Voices: A World Forum for Music Therapy, 11(1), https://doi.org/10.15845/voices.v11i1.291.

Coombes, E., \& Tombs-Katz, M. (2017). Interactive therapeutic music skill-sharing in the West Bank: An evaluation report of project Beit Sahour. Approaches: An Interdisciplinary Journal of Music Therapy, 9(1), 67-79.

Capriccio. (2017). We refugees. Retrieved February 18, 2017, from http://benjaminzephaniah.com/rhymin/we-refugees/

Freeman-Sharpe, E. (1978). Collected papers on psychoanalysis. London, England: Chatto \& Windus.

Jones, C. J., Baker, F., \& Day, T. (2004). From healing rituals to music therapy: Bridging the cultural divide between therapist and young Sudanese refugees. The Arts in Psychotherapy, 31(2), 89-100, https://doi.org/10.1016/j.aip.2004.02.002.

Oldfield, A., \& Bunce, L. (2001). Mummy can play too - short-term music therapy with mothers and young children. British Journal of Music Therapy, 15(1), 27-36, https://dx.doi.org/10.1177/13594575010500107.

Oldfield, A., Adams, M., \& Bunce, L. (2003). An investigation into short-term music therapy with mothers and young children. British Journal of Music Therapy, 17, 26-45, http://dx.doi.org/10.1177/135945750301700105.

Orth, J. (2005). Music therapy with traumatized refugees in a clinical setting. Voices: A World Forum for Music Therapy, 5(2), http://dx.doi.org/10.15845/voices.v5i2.227.

Pasiali, V. (2012). Resilience, music therapy, and human adaptation: nurturing young children and families. Nordic Journal of Music Therapy, 21(1), 36-56, https://dx.doi.org/10.1080/ 08098131.2011 .571276$.

Priestley, M. (1994). Essays in analytical music therapy. Philadelphia, PA: Barcelona Books.

Scroope, M., \& Signorelli, R. (2010). Music therapy helps traumatised refugees. Refugee Transitions, 23, 36-39.

Signorelli, R., \& Bright, R. (2006). From trauma to tope: A music therapy journey with refugees. Paper presented at the National Conference of the Australian Music Therapy Association Sydney, NSW.

Sutton, J. (2002). Music, Music Therapy and Trauma. England: Jessica Kingsley Publishers.

Stern, D. (2001). The interpersonal world of the infant: A view from psychoanalysis and developmental psychology. New York, NY: Basic Books.

Storsve, V., Westby, I. A., \& Ruud, E. (2010). Hope and recognition. A music project among youth in a Palestinian refugee camp. Voices; A World Forum for Music Therapy, 10(1), http://dx.doi.org/10.15845/voices.v10i1.158.

Winnicott, D. W. (1960). The Maturational Processes and the Facilitating Environment. England: Hogarth Press.

Winnicott, D. W. (1971). Playing and reality. England: Routledge. 
Zharinova-Sanderson, O. (2004). Promoting integration and socio-cultural change: Community music therapy with traumatized refugees in Berlin. In M. Pavlicevic \& G. Andsell (Eds.), Community music therapy (pp. 358-387). London, England: Jessica Kingsley Publishers. 